\title{
(5)

\section{Får kvinner nok informasjon til å ta informerte valg ved mammografiscreening?}

ORIGINALARTIKKEL

\section{BJØRN HOFMANN}

E-post: bjoern.hofmann@ntnu.no Institutt for helsevitenskap NTNU Gjøvik

og

Senter for medisinsk etikk

Universitetet i Oslo

Bjørn Hofmann er professor i medisinsk filosofi og etikk og forsker og underviser innenfor medisinsk filosofi, etikk, vitenskapsteori og teknologivurdering.

Forfatteren har fylt ut ICMJE-skjemaet og oppgir følgende interessekonflikter: Han har vært medlem av en uavhengig ekspertgruppe som har gitt innspill til Kreftregisteret i forbindelse med revisjonen av informasjonen for Mammografiprogrammet 2015-17. Innholdet i denne artikkelen er forfatterens eget og ikke uttrykk for Ekspertgruppen, Kreftregisteret eller Mammografiprogrammets analyser eller vurderinger. Kreftregisteret har publisert en egen omfattende rapport om prosessen.

\section{BAKGRUNN}

Mammografiscreening har skapt betydelig faglig og offentlig debatt. Denne studien undersøker hvorvidt kvinner får tilstrekkelig informasjon om nytte og ulempe ved det norske mammografiprogrammet til å kunne ta informerte og selvstendige valg.

\section{MATERIALE OG METODE}

Informasjonsmateriell fra det norske mammografiprogrammet for 1996, 2003, 2009 og 2017 ble analysert og sammenliknet med informasjonen fra den uavhengige granskingen av mammografiprogrammet ledet av Norges forskningsråd. Kriterier som er vesentlig for å ta informerte valg er: nytte (absolutt og relativ dødelighetsreduksjon), ulempe (falske testsvar, overdiagnostikk, overbehandling og engstelse), gjennomføring (etter innkalling og behandlingskrevende funn) og begrensning (intervallkreft).

\section{RESULTATER}

Informasjonen til kvinner er vesentlig forbedret fra 1996 til 2017. Likevel mangler informasjonen i 2017 viktige opplysninger om ulempene ved screening, som overdiagnostikk og overbehandling. 
Det norske mammografiscreeningsprogrammet gir ikke tilstrekkelig informasjon til at kvinner kan ta informerte og selvstendige valg. De inviterte «dyttes» til time ved at tidspunktet er forhåndsreservert, og informasjonen er ikke balansert og nyansert nok.

Det norske mammografiprogrammet feiret nylig sitt 2o-årsjubileum og har gjennomgått en ekstern og uavhengig evaluering styrt av Forskningsrådet (1). Programmet utmerker seg med høy deltagelse, gode registre og omfattende forskning. Nylig reviderte man informasjonen som gis ved invitasjonen. Dette var delvis drevet av ny kunnskap om utbyttet av screening og delvis av $\emptyset$ kt bevissthet om at informasjonen tidligere ikke har vært tilstrekkelig nyansert og balansert (2-5).

Men er informasjonen som gis god nok? Dette spørsmålet er særlig aktuelt etter at screeningprogrammer har blitt kritisert for å overselge nytte $(6,7)$ og for å ikke gi balansert informasjon tilpasset målgruppen (2-5, 8-10). Særlig har informasjon om risiko for falskt positive testresultater, overdiagnostikk og overbehandling vært underkommunisert. Flere studier viser i tillegg at kvinner har liten kunnskap om mammografiscreening og brystkreft $(8,9,11,12)$.

Denne studien undersøker hvorvidt mammografiscreeningsprogrammet gir kvinner tilstrekkelig informasjon om nytte og ulempe til at de kan ta informerte og selvstendige valg.

\section{Materiale og metode}

Informasjonsmateriell fra det norske mammografiprogrammet er innhentet august 2019. Det er samlet inn invitasjonsbrev, brosjyrer, faktaark, reservasjonsskjema, påminnelsesbrev og utskrifter fra nettsider. For å analysere den historiske utviklingen er informasjonsmateriell innhentet for $1996(13,14), 2003(15,16), 2009(17,18)$ og 2017 (19). Materialet er sammenlignet med følgende innholdselementer fra den uavhengige granskingen av mammografiprogrammet ledet av Norges forskningsråd (1): nytte (redusert risiko for død generelt og av brystkreft spesielt), ulempe (falske testsvar, overdiagnostikk, overbehandling og engstelse), gjennomføring (etter innkalling og behandlingskrevende funn) og begrensning (intervallkreft). Disse kriteriene er vesentlig for å ta informerte valg og er i tråd med hva som kreves i henhold til pasient- og brukerrettighetsloven §3 og § 4 . Innholdselementene som er brukt for dataekstraksjon er også i tråd med Mammografiprogrammets kvalitetsmanual (20).

Det ble foretatt en kvalitativt rettet innholdsanalyse (21). I tillegg til å vurdere de ulike elementene ble sitater markert og presenteres i resultatdelen. Teksten er også analysert med tanke på om innholdet kan være ledende for kvinnenes valg.

\section{Resultater}

Tabell 1 viser hvordan informasjonsmateriellet presenterer de ulike innholdselementene. Alt materiellet forklarer hva en mammografiundersøkelse er, hvem som inviteres, hvor lang tid undersøkelsen tar, behovet for tilleggsundersøkelser, hvordan kvinnen får resultatet samt praktisk informasjon til de som er brystkreftopererte eller har brystproteser. Med unntak av i materiellet fra 1996 står det også hva et screeningprogram er, hvordan undersøkelsen utføres og hvor man kan finne mer informasjon. Ikke noe av materiellet forklarer hva som vil skje dersom kvinnen skal behandles for brystkreft. Fra 2017 er dette imidlertid tilgjengelig på nettsiden. 
Innholdselementer $\mathrm{i}$ informasjonsmateriellet $\mathrm{i}$ de ulike revisjonene angitt ved årstall samt $\mathrm{i}$ den uavhengige granskingen ved Norges forskningsråd (NFR).

\begin{tabular}{|c|c|c|c|c|c|}
\hline & $1996(13-14)$ & $2003(15-16)$ & $2009(17-18)$ & 2017 (19) & $\begin{array}{l}\text { NFRs gransking } \\
\text { (1) }\end{array}$ \\
\hline $\begin{array}{l}\text { Redusert risiko for død } \\
\text { (total } \\
\text { dødelighetsreduksjon) }\end{array}$ & Ikke opplyst & Ikke opplyst & Ikke opplyst & Ikke opplyst & Ikke opplyst \\
\hline $\begin{array}{l}\text { Brystkreftspesifikk } \\
\text { dødelighetsreduksjon }\end{array}$ & $\begin{array}{l}\text { "Dødeligheten av } \\
\text { brystkreft kan reduseres } \\
\text { med om lag en tredjedel } \\
\text { ved systematiske } \\
\text { helseundersøelser med } \\
\text { mammografi.» }\end{array}$ & $\begin{array}{l}\text { "Jevnlig deltakelse } \mathrm{i} \\
\text { Mammografiprogrammet } \\
\text { reduserer risikoen for å dø } \\
\text { av brystkreft.» }\end{array}$ & $\begin{array}{l}\text { "Regelmessig mammografi } \\
\text { reduserer dødeligheten av } \\
\text { brystkreft.» } \\
\text { "Oppdager årlig om lag1 } \\
\text { ooo tilfeller av brystkreft } \\
\text { eller forstadier til } \\
\text { brystkreft.» }\end{array}$ & $\begin{array}{l}\text { "6 [av } 1000 \text { ] kvinner får } \\
\text { påvist brystkreft som må } \\
\text { behandless (i figur på } \\
\text { faktaarket). } \\
\text { "Den viktigste nytten ved } \\
\text { mammografiscreening er } \\
\text { at det fører til færre } \\
\text { dødsfall av brystkreft blant } \\
\text { kvinner i målgruppen.» }\end{array}$ & $\begin{array}{l}20-30 \% \text { for } \\
\text { kvinner mellom } \\
50 \text { og } 70 \text { år. } \\
27 \text { av } 10 \text { o00 } \\
\text { kvinner, } 50 \text { år, } \\
\text { screenet i } 10 \text { ăr, } \\
\text { som møtte } \\
10 \text { ganger og } \\
\text { med en } \\
\text { oppmøteprosent } \\
\text { på } 76 \% \text {. }\end{array}$ \\
\hline Falskt positive testsvar & Ikke opplyst & Ikke opplyst & $\begin{array}{l}\text { "Om lag } 4 \text { av } 100 \text { som } \\
\text { deltar, innkalles til } \\
\text { grundigere undersøkelse.» } \\
\text { "For de fleste viser det seg } \\
\text { at forandringene er ufarlige, } \\
\text { og dette omtales da som en } \\
\text { falsk positive } \\
\text { mammografiundersøkelse.» }\end{array}$ & $\begin{array}{l}24 \text { av } 1000 \\
\text { (Dette står ikke eksplisitt, } \\
\text { men må beregnes: } 30-6= \\
\text { 24). } \\
\text { Derimot står det: «18 } \\
\text { kvinner trenger nye } \\
\text { mammografibilder og/eller } \\
\text { ultralyd, og făr deretter } \\
\text { beskjed om at det ikke er } \\
\text { ondartede funn.» }\end{array}$ & $\begin{array}{l}20 \% \text { ved } \\
\text { deltagelse på } \\
\text { alle } \\
\text { undersøkelser i } \\
10 \text { år. } \\
1520 \text { av } 10000 \\
\text { fulgt i } 10 \text { år. }\end{array}$ \\
\hline Overdiagnostikk & Ikke opplyst & Ikke opplyst & $\begin{array}{l}\text { Ingen tall. } \\
\text { «Per i idag er det ikke mulig } \\
\text { a forutsi hvordan eller hvor } \\
\text { raskt et screening oppdaget } \\
\text { forstadium eller tilfelle av } \\
\text { brystkreft vil utvikkle seg." } \\
\text { "Det er uenighet i fagmiliøet } \\
\text { om hvor stort problemet } \\
\text { er.» }\end{array}$ & $\begin{array}{l}\text { Det gis ingen anslag. } \\
\text { «Mammografiscreening vil } \\
\text { innebære en risiko for } \\
\text { overdiagnostikk*. I dag er } \\
\text { det ikke mulig å skille ut } \\
\text { hvilke krefttilfeller som er } \\
\text { overdiagnostiserte, og } \\
\text { derfor făr alle med påvist } \\
\text { brystkreft tilbud om } \\
\text { behandling.» }\end{array}$ & $\begin{array}{l}142 \text { av } 10000 \\
15-25 \% \text { for } \\
\text { kvinner mellom } \\
50-79 \text { år } \\
\text { sammenlignet } \\
\text { med dem som } \\
\text { ikke får } \\
\text { invitasjon. } \\
15-20 \% \text { for } \\
\text { samme } \\
\text { aldersgruppe } \\
\text { om de blir } \\
\text { invitert. }\end{array}$ \\
\hline Overbehandling & Nevnes ikke & Nevnes ikke & Nevnes ikke & Nevnes ikke & $\begin{array}{l}\text { Nevnes, men } \\
\text { tallfestes ikke }\end{array}$ \\
\hline $\begin{array}{l}\text { Intervalllkreft (kreft } \\
\text { oppstått i perioden } \\
\text { mellom oppmøtene til } \\
\text { mammografiprogrammet) }\end{array}$ & $\begin{array}{l}\text { Nevnes ikke, men kvinner } \\
\text { oppordres til å undersøke } \\
\text { brystene selv. }\end{array}$ & $\begin{array}{l}\text { "Mammografi avdekker } \\
\text { ikke alle forandringer i } \\
\text { brystene." }\end{array}$ & $\begin{array}{l}\text { «Noen tilfeller av brystkreft } \\
\text { oppdages ikke ved } \\
\text { mammografi, eller oppstår i } \\
\text { tiden mellom to } \\
\text { mammografiundersøkelser.» }\end{array}$ & $\begin{array}{l}2 \text { av } 1000 . \\
\text { "2 kvinner [av } 1000 \text { vil] få } \\
\text { påvist brystkreft i iden før } \\
\text { neste undersøkelse." }\end{array}$ & $\begin{array}{l}25 \% \text { av alle som } \\
\text { deltar } i \\
\text { screening. } \\
127 \text { av } 10000 \\
\text { fulgt i } 10 \text { år. } \\
\text { Opplyser også } \\
\text { om } 42 \text { falskt } \\
\text { negative svar av } \\
10000 \\
\end{array}$ \\
\hline Engstelse, uro & Nevnes ikke & $\begin{array}{l}\text { "En innkallelse til } \\
\text { etterundersøkelse kan gi } \\
\text { engstelse, men som } \\
\text { deltager i det offentlige } \\
\text { programmet er du sikret } \\
\text { rask oppfølging." }\end{array}$ & $\begin{array}{l}\text { «Mange kan oppleve } \\
\text { engstelse og uro i } \\
\text { forbindelse med } \\
\text { mammografiundersøkelsen, } \\
\text { både i tiden fram til svar } \\
\text { foreligger og ved innkalling } \\
\text { til tilleggsundersøkelse.» }\end{array}$ & $\begin{array}{l}\text { "l forbindelse med } \\
\text { mammografiundersøkelsen } \\
\text { kan man oppleve engstelse } \\
\text { og uro, både i tiden fram til } \\
\text { svaret foreligger og ved } \\
\text { innkalling til } \\
\text { tilleggsundersøkelse.» }\end{array}$ & $\begin{array}{l}\text { Nevnes, men } \\
\text { tallfestes ikke }\end{array}$ \\
\hline Etter innkalling & $\begin{array}{l}1 \text { av } 20, \\
5 \text { av } 100\end{array}$ & 3 av 100 & 4 av 100 & 3 av 100 & $\begin{array}{l}1520 \text { av } 10000 . \\
20 \% \text { etter } 10 \\
\text { invitasjoner }\end{array}$ \\
\hline $\begin{array}{l}\text { Antall } \\
\text { behandlingskrevende } \\
\text { funn }\end{array}$ & Ikke opplyst & 6 av 1000 & $5-6$ av 1000 & 6 av 1000 & \\
\hline Potensielt ledende tekst & $\begin{array}{l}\text { "Tenk på fremtiden din - } \\
\text { benytt deg av tilbudet om } \\
\text { mammografiundersøkelse!» } \\
\text { «Dette tilbudet bør du } \\
\text { benytte deg av.» } \\
\text { «En } \\
\text { mammografiundersøkelse } \\
\text { kan redde liv." }\end{array}$ & $\begin{array}{l}\text { «En } \\
\text { mammografiundersøkelse } \\
\text { kan redde liv.» } \\
\text { «Tidlig diagnose, enklere } \\
\text { behandling, bedre } \\
\text { leveutsikter.» } \\
\text { "Deltagelse i } \\
\text { Mammografiprogrammet } \\
\text { sikrer rask oppøølging.» } \\
\text { «Vi håper du velger å delta } \\
\text { idet offentlige } \\
\text { Mammografiprogrammet.» }\end{array}$ & $\begin{array}{l}\text { "Tre av fire inviterte kvinner } \\
\text { velger å delta.» } \\
\text { "Regelmessig mammografi } \\
\text { er i dag den viktigste } \\
\text { metoden for å oppdage } \\
\text { brystkreft i et tidlig } \\
\text { stadium.» }\end{array}$ & $\begin{array}{l}\text { «Vi setter stor pris på } \\
\text { beskjed dersom du ikke } \\
\text { kommer, da kan andre ha } \\
\text { glede av din time.» } \\
\text { «Vil du delta i } \\
\text { Mammografiprogrammet?» }\end{array}$ & \\
\hline
\end{tabular}

Total dødelighetsreduksjon blir ikke opplyst i noe av informasjonsmateriellet. Før 2017 var det heller ikke eksplisitt informert om brystkreftspesifikk dødelighetsreduksjon. Det gis ikke eksplisitt informasjon om antall falskt positive mammografiundersøkelser, men fra 2009 beskrives falskt positive funn og i 2017 er det mulig å regne ut hvor mange det er per 1 ooo kvinner.

Overdiagnostikk blir nevnt først i 2009, men det informeres ikke om omfanget av dette, heller ikke i 2017. Overbehandling, falskt negative testsvar eller byrden ved behandling nevnes ikke eksplisitt i noe av informasjonsmateriellet. Av andre ulemper nevnes risikoen knyttet til ioniserende stråling. Med unntak av informasjonen fra 2017 er stråledose nevnt og opplyst å være lav og med liten helserisiko. Konfidensintervaller blir ikke oppgitt for noen av tallverdiene.

Alt informasjonsmateriell understreker nytten av tidlig oppdagelse av kreft, og i noe av det fremheves endret behandlingsforløp ved tidligere oppdagelse: «Tidlig diagnose, enklere behandling, bedre leveutsikter» og «Deltagelse i Mammografiprogrammet sikrer rask oppfølging». Ingen nevner at forbedret brystkreftbehandling og redusert 
hormonbehandling i forbindelse med overgangsalderen også bidrar til redusert brystkreftdødelighet.

Alt informasjonsmateriell inneholder tekst som kan oppfattes som ledende (tabell 1 ). Det har skjedd en stor endring fra 1996, da kvinnene klart ble oppfordret til å delta: «Tenk på fremtiden din», «Dette tilbudet bør du benytte deg av» og "En mammografiundersøkelse kan redde liv» til 2017: «Vil du delta i Mammografiprogrammet?».

I tillegg inviteres hver kvinne med en gitt dato og tidspunkt for selve mammografiundersøkelsen. For kvinner som ikke ønsket å delta, har informasjonen endret seg fra 1996 til 2017. I 1996 var det ingen informasjon om hva man skulle gjøre om man ikke $\emptyset$ nsket å delta. I 2003 kunne kvinnen fylle ut et reservasjonsskjema med informasjon om reservasjonen var midlertidig eller fullstendig, samt angi grunnen for at hun ikke ønsket å inviteres. Videre skulle hun også oppgi personnummer og samtykket automatisk til at dataene kunne brukes til forskning. I 2009 inneholdt skjemaet tre alternativer: deltagelse neste gang, tidsbegrenset reservasjon og fullstendig reservasjon. Samtidig var det frivillig å oppgi grunner til reservasjon, og det var ikke automatisk samtykke til å delta i forskning. I informasjonen fra 2017 blir man bedt om å oppsøke Kreftregisterets nettside, ringe eller sende e-post dersom man ikke ønsker å delta eller vil reservere seg. Fra nettsiden blir man lenket til sikker elektronisk løsning eller man kan laste ned et reservasjonsskjema som ligner på skjemaet fra 2009 .

\section{Diskusjon}

I en tid der individuelle valg vektlegges og tilgang til informasjon er overveldende og av varierende kvalitet, er god informasjon om helsetiltak særdeles viktig. Det gjelder spesielt for helsetiltak som ikke er nødvendige, men som er avhengige av den enkeltes preferanser, slik mammografiscreening er. Resultatene viser at informasjonen fra mammografiprogrammet er vesentlig forbedret fra 1996 til 2017. Samtidig er ikke viktige informasjonselementer om ulemper tilgjengelige i informasjonsmateriellet.

Tidligere er det gitt informasjon det ikke er hold i. For eksempel har det stått at regelmessig mammografi gir «bedre leveutsikter», men ingen studier kan vise til redusert totaldødelighet som følge av mammografiscreening.

Ett viktig funn i denne studien er mangelen på informasjon om overdiagnostikk. Overdiagnostikk fikk lite oppmerksomhet fra forskere før 2004. I dag er dette godt kjent og dokumentert i Norge. Likevel opplyses ikke kvinner konkret om denne faren (19). Dette er særlig oppsiktsvekkende, da forskere tilknyttet Kreftregisteret selv har publisert data rundt overdiagnostikk (22). Det er vanskelig å forsvare at kvinner ikke informeres, for eksempel gjennom tall fra den uavhengige granskingen av programmet (1). Manglende informasjon om ulemper er i samsvar med det som beskrives i internasjonal litteratur (23). Europeiske retningslinjer (24) og Verdens helseorganisasjon spesifiserer 70 \% deltagelse som en sentral kvalitetsindikator for mammografiscreening (25) og anbefaler at informasjonsmateriellet fremmer deltagelse (26). Som et resultat av dette bruker Kreftregisteret for eksempel Facebook til å oppfordre kvinner i distrikter der deltakelsen er «dårligst i landet» til å møte opp på screening. Fokus på oppmøte som en kvalitetsindikator kan føre til at potensiell nytte overvurderes og at mulige ulemper underkommuniseres $(12,27,28)$.

Universitetet i Sydney, som har arbeidet og forsket mye på kommunikasjon av informasjon om screeningprogrammer, har lagd et godt eksempel på informasjon som kvinner trenger for å ta et informert valg, Making a choice: summary of over 25 years with and without screening (29). Der er informasjon om nytte og ulempe gitt i absolutte tall og sammenliknet med samme enhet (per 1 ooo kvinner screenet), se tabell 2. Tilsvarende informasjon er tilgjengelig fra National Health Service (NHS) Scotland (30). I Skottland informeres også kvinnene om risikoen for kreft fra stråling ved mammografiundersøkelsen: «For every 14,00o woman screened regularly for 10 years, 1 woman may develop breast cancer because of this radiation.» 
Tabell 2

Informasjon utarbeidet ved Universitetet i Sydney, Making a choice: summary of over 25 years with and without screening (29).

\begin{tabular}{|c|c|c|}
\hline Kjernespørsmål & $\begin{array}{l}\text { Mammografiundersøkelser i } 25 \\
\text { år fra } 50 \text { års alder }\end{array}$ & $\begin{array}{l}\text { Ingen } \\
\text { mammografiundersøkelser i } 25 \\
\text { år fra } 50 \text { års alder }\end{array}$ \\
\hline $\begin{array}{l}\text { Hva er sjansene } \\
\text { for å dø av } \\
\text { brystkreft? }\end{array}$ & $\begin{array}{l}14 \text { av } 1000 \text { kvinner dør av } \\
\text { brystkreft. }\end{array}$ & $\begin{array}{l}19 \text { av } 1000 \text { kvinner dør av } \\
\text { brystkreft. }\end{array}$ \\
\hline $\begin{array}{l}\text { Hva er sjansene } \\
\text { for å bli } \\
\text { diagnostisert og } \\
\text { behandlet for } \\
\text { brystkreft som } \\
\text { ikke er skadelig for } \\
\text { meg? }\end{array}$ & $\begin{array}{l}30 \text { av } 1000 \text { blir diagnostisert og } \\
\text { behandlet for brystkreft som } \\
\text { ikke er skadelig } \\
\text { (overdiagnostikk). }\end{array}$ & $\begin{array}{l}0 \text { av } 1000 \text { kvinner. } \\
\text { Kvinner som ikke går til } \\
\text { mammografiscreening vil ikke } \\
\text { oppleve å bli overdiagnostisert } \\
\text { og overbehandlet. }\end{array}$ \\
\hline $\begin{array}{l}\text { Hva er sjansene } \\
\text { for at jeg får et } \\
\text { falskt positivt svar } \\
\text { som fører til ekstra } \\
\text { undersøkelser? } \\
\end{array}$ & $\begin{array}{l}465 \text { av } 1000 \text { kvinner får falskt } \\
\text { positive mammografisvar og } \\
\text { ekstra testing uten at de har } \\
\text { kreft. }\end{array}$ & $\begin{array}{l}0 \text { av } 1000 . \\
\text { Kvinner som ikke går til } \\
\text { mammografiscreening, vil ikke } \\
\text { oppleve falskt positive testsvar. }\end{array}$ \\
\hline $\begin{array}{l}\text { Hva trenger jeg å } \\
\text { gjøre? }\end{array}$ & $\begin{array}{l}\text { Om du bestemmer deg for å } \\
\text { delta i screeningprogrammet, vil } \\
\text { du inviteres til screening } \\
\text { annethvert år i } 25 \text { år. } \\
\text { Om du oppdager symptomer i } \\
\text { brystet, må du oppsøke din lege. }\end{array}$ & $\begin{array}{l}\text { Om du ikke ønsker å delta i } \\
\text { screeningprogrammet nå, kan } \\
\text { du alltid ombestemme deg i } \\
\text { fremtiden. } \\
\text { Om du oppdager symptomer i } \\
\text { brystet, må du oppsøke din lege. }\end{array}$ \\
\hline
\end{tabular}

En av utfordringene med informasjon om effekter av mammografiscreening er at forskningsresultatene spriker både når det gjelder nytte og ulempe (1,31). Basert på tallmateriale fra Norge varierer de relative tallene for reduksjon i brystkreftspesifikk dødelighet mellom $7 \%$ og $30 \%$, og mellom $7 \%$ og $52 \%$ for overdiagnostikk (1). Mammografiscreeningsprogrammet har nylig hatt en grundig prosess for å vurdere og forbedre informasjonsmateriellet sitt (32). Likevel tilfredsstiller de ikke sine egne kvalitetskriterier (20).

Når viktige informasjonselementer mangler, kan det skyldes sterke interesser hos aktørene. Det er ikke vanskelig å forstå at de som til daglig arbeider med mammografi, ser dette som svært meningsfullt. At myndighetene fremmer det de oppfatter som et gode, er også forståelig. De har investert betydelige ressurser og prestisje i programmet. Men når entusiasmen reduserer kvinners mulighet til å ta informerte og selvstendige valg, blir dette problematisk. Kreftregisteret informerer i foredrag og på nettsider at reduksjon $\mathrm{i}$ brystkreftdødeligheten er på $43 \%$ (33-35), til tross for at en rekke studier og den uavhengige granskingen viser at reduksjonen i brystkreftdødelighet er lavere (1).

Et annet viktig funn er at alle kvinner får invitasjon til mammografiscreening som inneholder informasjon om dato, tid og sted for unders $\emptyset$ kelsen. Tidligere var det vanskeligere «å avbestille time» og man måtte oppgi grunn. Selv om dette har blitt vesentlig bedre, kan likevel slike forhåndsreservasjoner gjøre at invitasjonsbrev oppfattes som innkallinger (36) eller anbefalinger der man har et ansvar for å møte opp (37). Dette er en form for «dytting» (nudging) som reduserer den enkeltes mulighet til å ta informerte og selvstendige valg (38).

Metoden i denne studien er enkel og lett etterprøvbar, men den har noen begrensninger. For det første har kvinner mange andre kilder til informasjon enn den som gis av Mammografiprogrammet. Mange tar også sine beslutninger helt uavhengig av slik informasjon og baserer seg på erfaringer og råd fra slekt og venner. Slik sett kan kvinner ta informerte og selvstendige valg selv om den offentlige informasjonen er mangelfull. 
For det andre begrenser denne studien seg til teksten i materialet. En nærmere analyse av figurer, bilder og farger kunne gitt viktig kunnskap om hvordan man ønsker å formidle og påvirke leseren. De utvalgte kriteriene for informasjonselementer brukt i denne studien kan diskuteres, men de ble valgt basert på solid forskning $(39,40)$ og stemmer overens med Mammografiprogrammets egne kvalitetsmanual (20).

Studien tar for gitt at kvinner skal informeres på en måte som muliggjør selvstendige, informerte valg. Noen kan selvsagt fortsatt hevde at folkehelsen er viktigere enn individets valg, slik det har vært tradisjon for (12). Det kan også hende at etterspørselen etter mammografiscreening drives av en regissert risikoaversjon, der informasjonsinnhold uansett har liten betydning for kvinnens beslutning (41). Noen vil også mene at selvstendige og informerte valg er en illusjon. Likevel kan det være verdifullt å undersøke om informasjonsmateriellet støtter oppunder slike oppfatninger og om det forholder seg til idealer nedtegnet i det norske lovverket.

\section{Konklusjon}

Mammografiprogrammet har gjort vesentlige forbedringer i informasjonen siden 1996. Likevel gis det fortsatt ikke tilstrekkelig informasjon til at kvinner kan ta informerte og selvstendige valg. Det mangler blant annet relevante estimat for ulempene, særlig om overdiagnostikk. Videre dyttes de inviterte gjennom forhåndsavtaler, som gjør at invitasjonsbrevene kan oppfattes som innkallinger og ikke som tilgang til balansert informasjon.

\section{HOVEDFUNN}

Mammografiprogrammet forbedret sin informasjon vesentlig fra 1996 til 2017, men det var i 2017 fortsatt ikke tilstrekkelig informasjon til at kvinner kunne ta informerte og selvstendige valg.

Invitasjonsbrevene inneholdt forhåndsavtaler som kunne oppfattes som innkallinger, og det ble ikke gitt balansert informasjon.

\section{LITTERATUR:}

1. The Norwegian Research Council. Research-based evaluation of the Norwegian Breast Cancer Screening Program. Oslo: The Norwegian Research Council, 2015.

2. Croft E, Barratt A, Butow P. Information about tests for breast cancer: what are we telling people? J Fam Pract 2002; 51: 858-6o. [PubMed]

3. Jørgensen KJ, Zahl PH, Gøtzsche PC. Overdiagnosis in organised mammography screening in Denmark. A comparative study. BMC Womens Health 2009; 9:36. [PubMed][CrossRef]

4. Thornton $\mathrm{H}$, Edwards A, Baum M. Women need better information about routine mammography. BMJ 2003; 327: 101-3. [PubMed][CrossRef]

5. Luqmani YA. Breast screening: an obsessive compulsive disorder. Cancer Causes Control 2014; 25: 1423-6. [PubMed][CrossRef]

6. Zahl PH, Kalager M, Suhrke P et al. Quality-of-life effects of screening mammography in Norway. Int J Cancer 2019; 145: ijc.32539. [PubMed][CrossRef]

7. Biller-Andorno N, Jüni P. Abolishing mammography screening programs? A view from the Swiss Medical Board. N Engl J Med 2014; 370: 1965-7. [PubMed][CrossRef]

8. Webster P, Austoker J. Women's knowledge about breast cancer risk and their views of the purpose and implications of breast screening-a questionnaire survey. J Public Health (Oxf) 2006; 28: 197-202. [PubMed][CrossRef]

9. Gigerenzer G, Mata J, Frank R. Public knowledge of benefits of breast and prostate cancer screening 
in Europe. J Natl Cancer Inst 2009; 101: 1216-20. [PubMed][CrossRef]

10. Slaytor EK, Ward JE. How risks of breast cancer and benefits of screening are communicated to women: analysis of 58 pamphlets. BMJ 1998; 317: 263-4. [PubMed][CrossRef]

11. Domenighetti G, D’Avanzo B, Egger M et al. Women's perception of the benefits of mammography screening: population-based survey in four countries. Int J Epidemiol 2003; 32: 816-21.

[PubMed][CrossRef]

12. Østerlie W, Solbjør M, Skolbekken JA et al. Challenges of informed choice in organised screening. J Med Ethics 2008; 34: e5. [PubMed][CrossRef]

13. Invitasjon til mammografiundersøkelse. Oslo: Kreftregisteret, 1996.

14. En mammografiundersøkelse kan redde liv. Oslo: Kreftregisteret, 1996.

15. Invitasjon til Mammografiprogrammet. Oslo: Kreftregisteret, 2003.

16. Mammografi kan redde liv. Oslo: Kreftregisteret, 2003.

17. Invitasjon til deltagelse i Mammografiprogrammet. Oslo: Kreftregisteret, 2009.

18. Mammografi kan redde liv. Oslo: Kreftregisteret, 2009.

19. Vil du delta i Mammografiprogrammet? Oslo: Kreftregisteret, 2017.

https://www.kreftregisteret.no/globalassets/mammografiprogrammet/informsjonsmateriell/invitasjo n_bokmal.pdf Lest 13.1.2020.

20. Ertzaas A. Kvalitetsmanual Mammografiprogrammet. Oslo: Kreftregisteret, 2003.

https://www.kreftregisteret.no/globalassets/publikasjoner-og-rapporter/mammografiprogrammet/kv alitetsmanual_mammografiprogrammet.pdf Lest 13.1.2020.

21. Hsieh HF, Shannon SE. Three approaches to qualitative content analysis. Qual Health Res 2005; 15: 1277-88. [PubMed][CrossRef]

22. Falk RS, Hofvind S, Skaane P et al. Overdiagnosis among women attending a population-based mammography screening program. Int J Cancer 2013; 133: 705-12. [PubMed][CrossRef]

23. Zorzela L, Loke YK, Ioannidis JP et al. PRISMA harms checklist: improving harms reporting in systematic reviews. BMJ 2016; 352: i157. [PubMed][CrossRef]

24. Amendoeira I, Perry N, Broeders M et al. European guidelines for quality assurance in breast cancer screening and diagnosis. Brussel: Europakommisjonen, 2013.

25. World Health Organization. Screening.

https://www.who.int/cancer/prevention/diagnosis-screening/screening/en/ Lest 13.1.2020.

26. European Commission Initiative on Breast Cancer. Invite and inform women about organised screening programmes.

https://healthcare-quality.jrc.ec.europa.eu/european-breast-cancer-guidelines/Invitation-to-screeningand-decision-aid Lest 13.1.2020.

27. Raffle AE. Information about screening - is it to achieve high uptake or to ensure informed choice? Health Expect 2001; 4: 92-8. [PubMed][CrossRef]

28. Camilloni L, Ferroni E, Cendales BJ et al. Methods to increase participation in organised screening programs: a systematic review. BMC Public Health 2013; 13: 464. [PubMed][CrossRef]

29. Hersch J. Breast cancer screening: It's your choice. Sydney: University of Sydney, 2017.

https://ses.library.usyd.edu.au/bitstream/handle/2123/16658/2017\%2oupdated\%2obreast\%2oscreening\%2 oDA\%2o(Hersch\%2oet\%2oal).pdf;jsessionidA5793B4298BE35FAE5199Do93A2AF4DD?sequence=1 Lest 13.1.202O.

30. NHS Scotland. Make time for breast screening. Glasgow: NHS Scotland, 2019.

http://www.healthscotland.com/uploads/documents/507o-Make\%2otime\%2ofor\%2obreast\%2oscreenin g\%2obooklet-May2019-English.pdf Lest 13.1.2020.

31. Marmot MG, Altman DG, Cameron DA et al. The benefits and harms of breast cancer screening: an independent review. Br J Cancer 2013; 108: 2205-40. [PubMed][CrossRef]

32. Hofvind S, Mangerud G, Ertzaas AKO et al. Prosjektrapport: Revisjon av informasjonsmateriellet i Mammografiprogrammet. Oslo: Kreftregisteret, 2019. 
https://www.kreftregisteret.no/globalassets/mammografiprogrammet/rapporter-og-publikasjoner/20 190327-mammografi-prosjektrapport-2703.pdf Lest 13.1.2020.

33. Kreftregisteret. Offentlig mammografiscreening redder liv og reduserer overbehandling. https://www.kreftregisteret.no/Generelt/Nyheter/Offentlig-mammografiscreening-redder-liv-og-redus erer-overbehandling-/ Lest 13.1.2020.

34. Kreftregisteret. Nye dødelighetstall i tråd med tidligere europeiske studier.

https://www.kreftregisteret.no/Generelt/Nyheter/Nye-dodelighetstall-i-trad-med-tidligere-europeisk e-studier/ Lest 13.1.2020.

35. Hofvind S, Ursin G, Tretli S et al. Breast cancer mortality in participants of the Norwegian Breast Cancer Screening Program. Cancer 2013; 119:3106-12. [PubMed][CrossRef]

36. Jørgensen KJ, Brodersen J, Hartling OJ et al. Informed choice requires information about both benefits and harms. J Med Ethics 2009;35: 268-9. [PubMed][CrossRef]

37. Beck U, Beck-Gernsheim E. Institutionalized individualism and its social and political consequences. Ann Arbor: University of Michigan Press, 2002.

38. Ploug T, Holm S, Brodersen J. To nudge or not to nudge: cancer screening programmes and the limits of libertarian paternalism. J Epidemiol Community Health 2012; 66: 1193-6. [PubMed][CrossRef]

39. Gummersbach E, Piccoliori G, Zerbe CO et al. Are women getting relevant information about mammography screening for an informed consent: a critical appraisal of information brochures used for screening invitation in Germany, Italy, Spain and France. Eur J Public Health 2010; 20: 409-14. [PubMed][CrossRef]

40. Hofmann J, Kien C, Gartlehner G. Comparative evaluation of information products regarding cancer screening of German-speaking cancer organizations. Z Evid Fortbild Qual Gesundhwes 2015; 109:350-62. [PubMed][CrossRef]

41. Aronowitz RA. Unnatural history: Breast cancer and American society. New York, NY: Cambridge University Press, 2007.

Publisert: 16. februar 2020. Tidsskr Nor Legeforen. DOI: 10.4045/tidsskr.19.0568

Mottatt 8.9.2019, første revisjon innsendt 9.12.2019, godkjent 13.1.2020.

(C) Tidsskrift for Den norske legeforening 2020. Lastet ned fra tidsskriftet.no 